Please do not remove this page

RMIT

UNIVERSITY

\title{
Flip-chip bonded stacked patch antenna for monolithic microwave integrated circuits
}

Elmezughi, Abdurrezagh; Rowe, Wayne

https://researchrepository.rmit.edu.au/esploro/outputs/9921862590401341/filesAndLinks?institution=61RMIT_INST\&index=null

Elmezughi, A., \& Rowe, W. (2006). Flip-chip bonded stacked patch antenna for monolithic microwave integrated circuits. Proceedings of the 2006 Asia-Pacific Microwave Conference.

https://doi.org/10.1109/APMC.2006.4429513

Published Version: https://doi.org/10.1109/APMC.2006.4429513

Repository homepage: https://researchrepository.rmit.edu.au

(c) 2006 IEEE. Personal use of this material is permitted. However, permission to reprint/republish this material for advertising or promotional purposes or for creating new collective works for resale or redistribution to servers or lists, or to reuse any copyrighted component of this work in other works must be obtained from the IEEE.

Downloaded On 2023/04/26 17:57:34 +1000 


\title{
Flip-Chip Bonded Stacked Patch Antenna for Monolithic Microwave Integrated Circuits
}

\author{
A. S. Elmezughi and W. S. T. Rowe
}

School of Electrical and Computer Engineering, RMIT University, Melbourne, Victoria, 3001, Australia

Tel: +61 39925 3968, Fax: +61 39925 2007, E-mail: wayne.rowe@ @mit.edu.au

\begin{abstract}
This paper presents the design and simulation of a stacked patch antenna with a proximity coupled feed realized via a flip-chip bonding process. The antenna uses high and low dielectric constant materials and is compatible to Monolithic Microwave Integrated Circuits. The antenna achieves a bandwidth of $23.8 \%$ (VSWR < 2) centered at frequency of $13 \mathrm{GHz}$ and has a gain of $5.3 \mathrm{dBi}$.
\end{abstract}

Index Terms - Flip-chip bonding, microstrip antennas, millimeter-waves, proximity coupled.

\section{INTRODUCTION}

The last several years have seen a push to incorporate the salient characteristics of microstrip antennas (low profile, low manufacturing cost, light weight, ease of fabrication) with Monolithic Microwave Integrated Circuit (MMIC) technology. However, MMIC compatible microstrip antennas encounter many problems which arise due to the high permittivity of MMIC substrate/wafer. Conventional microstrip antennas on high permittivity materials have an inherently narrow bandwidth, typically only a few percent. They can also be prone to excessive excitation of surface waves which degrade the antenna efficiency and destructively impact on the radiation pattern of the antenna. Many techniques have been introduced in the literature to overcome these problems. The quasi-yagi antenna [1] shows very broadband performance on high dielectric constant materials, displaying a 50\% impedance bandwidth. However, it is possible that there is some surface wave generation, as the gain of the antenna is moderate ( 3 to $5 \mathrm{dBi}$ ) and it has an end-fire radiation pattern. A stacked patch antenna using a combination of high and low permittivity layers was reported in [2] with a $25 \%$ bandwidth. This hi-lo stacked patch also had impressive efficiency for a MMIC compatible structure. The drawback of this antenna is that one of the radiating elements is directly integrated on the same layer as the rest of the circuit, which swallows up a large amount of real estate on the MMIC chip. In [3], a MMIC compatible stacked patch displayed a bandwidth in excess of $21 \%$. Due to the proximity coupled feed configuration this antenna consumed minimal space on the feed substrate, which would be the MMIC wafer in an integration scenario.

At millimeter wave frequencies, many limitations have to be overcome in order to design a microstrip antenna with acceptable performance on a high dielectric substrate. Millimeter wave antennas [4] exhibit a number of advantages like wide frequency range (for only a small percentage bandwidth), small size and generally light weight. However, millimeter wave stacked patch antennas are prone to misalignment of the substrate layers. At millimeter wave frequencies, even a fraction of a millimeter offset in the upper layer of a stacked patch can cause degradation in antenna performance.

Flip-chip bonding is a well established technology for improving the performance of MMIC interconnections and reducing fabrication costs. Many applications have been reported using flipchip bonding techniques which display the requirements and quality for mm-wave applications [5]. Flip-chip bonding involves directly bonding two substrates face to face through conducting bumps deposited on the base substrate. This process provides the shortest possible signal path with good microwave performance and significant circuit miniaturization. Flip-chip bonding relies on the accurate placement of the superstrate layer to ensure all bond connections make satisfactory electrical contact. 


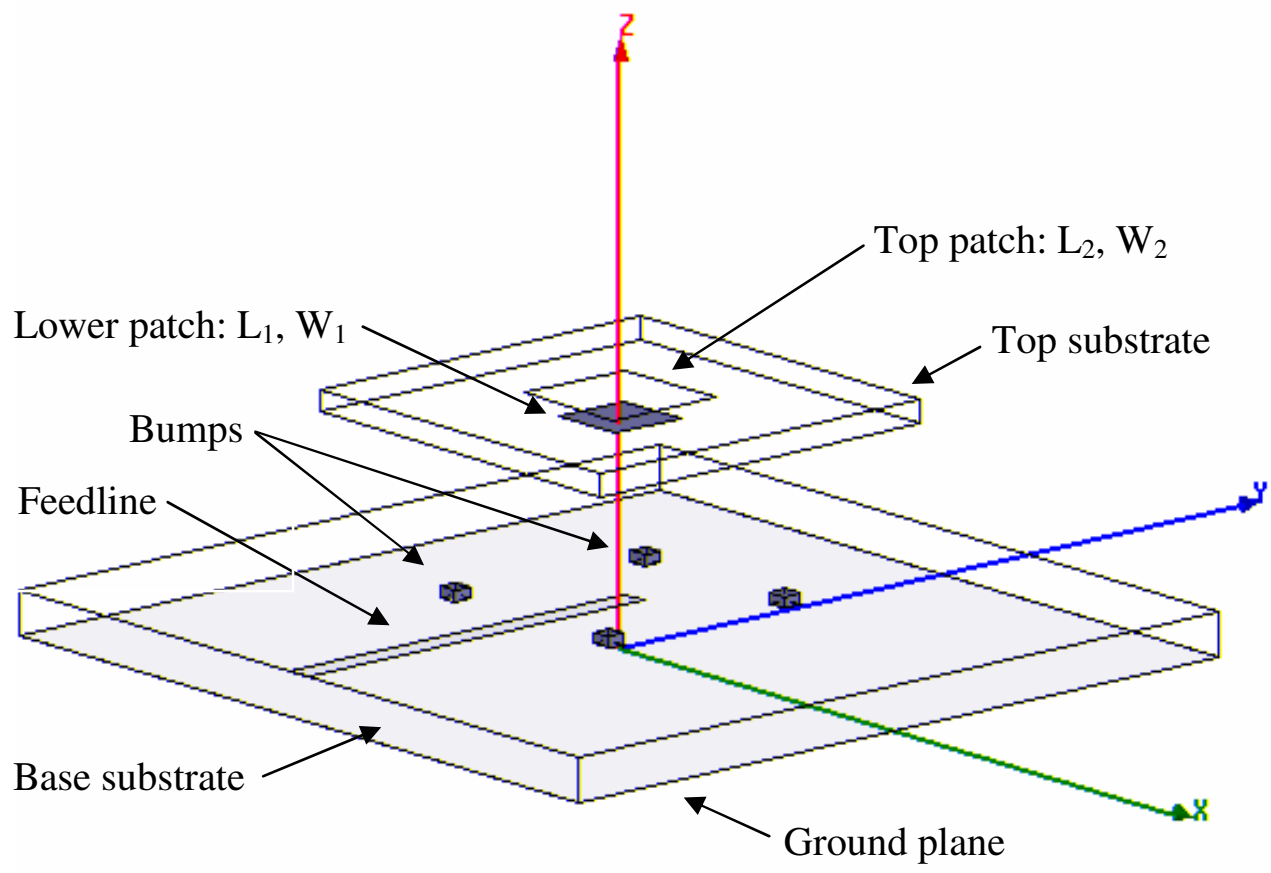

Figure 1. Geometry of the proposed antenna.

Parameters $-\mathrm{L}_{1}=4.1 \mathrm{~mm}, \mathrm{~W}_{1}=4.1 \mathrm{~mm}, \mathrm{~L}_{2}=6 \mathrm{~mm}, \mathrm{~W}_{2}=6 \mathrm{~mm}$, feedline width $=0.6 \mathrm{~mm}$, bump height $\mathrm{h}=0.03 \mathrm{~mm}$, base substrate: $\mathrm{h}=0.635 \mathrm{~mm}, \varepsilon_{\mathrm{r}}=9.6, \tan \delta=0.0023$, top substrate: $\mathrm{h}=1.575 \mathrm{~mm}, \varepsilon_{\mathrm{r}}=2.2, \tan \delta=0.0009$.

In this paper we present a stacked patch antenna with a proximity coupled feed which flip-chip bonds two different types of dielectric material (in the hi-lo permittivity configuration). The antenna is compatible with MMIC technology, with the objective of achieving good performance through the high accuracy placement and rigid attachment of the upper substrate layer.

\section{ANTENNA STRUCTURE}

Figure 1 shows the basic geometry of the proposed proximity coupled stacked patch antenna. A $50 \Omega$ microstrip feed line of $0.6 \mathrm{~mm}$ width is situated on the top side of a ceramic wafer which has a thickness of $0.635 \mathrm{~mm}$ and a high dielectric constant of 9.6. The feed line was produced via a photolithographic process on a $\mathrm{Ti}-\mathrm{Ni}$-Au seed layer, and electroplated to a thickness of approximately 8 $\mu \mathrm{m}$. The feed line extends $1.15 \mathrm{~mm}$ past the center of the lower patch. A ground plane is formed on the reverse side using the same seed layer and electroplating process. The flip-chip bumps are 0.2 mm square, and patterned on the base substrate at an $\mathrm{x}$-y offset of $( \pm 3.8, \pm 3.8) \mathrm{mm}$ relative to the centre of the patch elements. The bumps were electroplated to a height of $30 \mu \mathrm{m}$. In this antenna structure the flip-chip bumps are not used as a signal connection. They are used to enable the flip-chip process, allowing the accurate placement of the antenna elements on the top substrate. The flipchips bumps create an air gap between the feed line and the lower patch of approximately $30 \mu \mathrm{m}$ in the assembled antenna structure. The closeness of the feed line to the lower patch makes the power coupling very strong. The lower patch element is etched on the underside of a $1.575 \mathrm{~mm}$ thick Rogers RT/Duroid 5880 substrate (top substrate) which is $8.5 \times 8.5 \mathrm{~mm}$ in size. A second patch (top patch) on the upper side of this substrate is mutually coupled to the lower patch. This substrate also contains bonding pads on the underside that will be aligned to the gold bumps on the base substrate during the flipchip bonding process. The two substrates will be brought into contact and bonded by pressure, heat and ultrasonic vibration to fuse the bumps on the base substrate to the pads on the top substrate. The 
high accuracy placement and rigid attachment of the upper substrate layer, this antenna has the propensity to be scaled up to millimeter wave operation frequencies.

\section{RESULTS AND DISCUSSION}

The HFSS software package (version 9.2) has been used to analyze the proposed flip-chip antenna structure. Figure 2 shows the simulated input impedance versus frequency. The impedance response shows a bandwidth of $23.8 \%$ (for VSWR $<2$ ) is achieved, centered at approximately $13 \mathrm{GHz}$. This bandwidth is comparable to other proximity coupled stacked patch antennas [3]. As the final height of the gold bumps after the flip-chip bonding process is not accurately know at this stage, a parameter study was performed which varied the bump height, and hence altered the air gap in between the substrate layers of the antenna. The simulated results of this study showed how changes in the height of the bumps (and air gap) affect the impedance response (Figure 2) and the gain (Figure 3 ) of the antenna. By increasing the height of the bumps (air gap) to $40 \mu \mathrm{m}$ the input impedance is relatively similar to the case when the height is 30 $\mu \mathrm{m}$. However, if the bump height is decreased (to $20 \mu \mathrm{m}$ ), the return loss across the impedance bandwidth drops resulting in a decreased bandwidth. This is due to the feedline coupling too strongly to the lower patch.
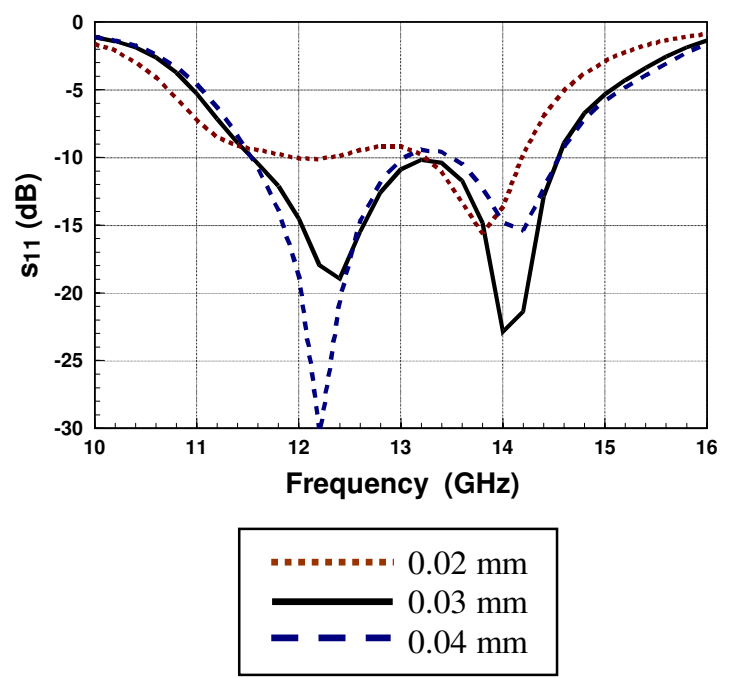

Figure 2. Simulated return loss versus frequency of the proposed antenna, as a function of the flip-chip bump height (in $\mathrm{mm}$ ).

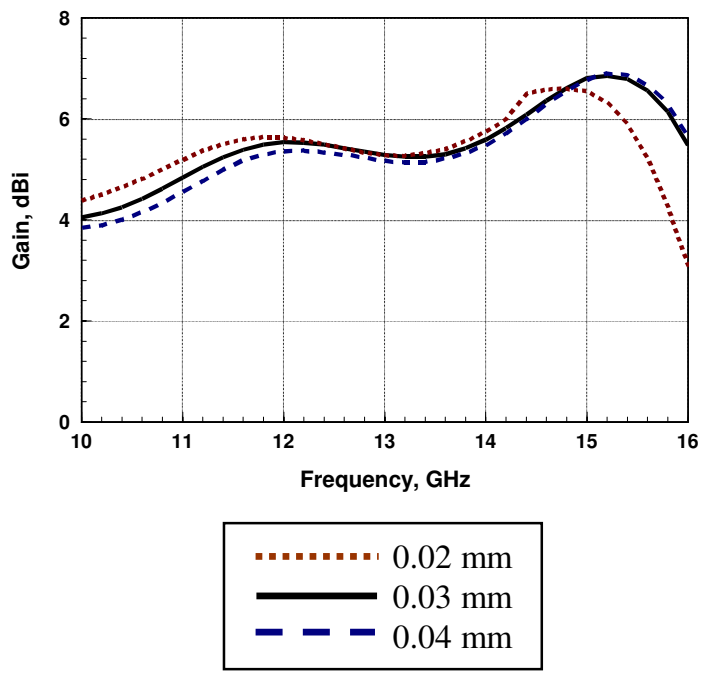

Figure 3. Simulated gain of the proposed flip-chip antenna, as a function of the flip-chip bump height (in $\mathrm{mm}$ ).

The simulated gain of the flip-chip proximity coupled antenna is shown in Figure 3. The peak gain of the proposed antenna is $6.1 \mathrm{dBi}$ and the gain remains fairly constant across the impedance bandwidth from $11.5 \mathrm{GHz}$ to $14.6 \mathrm{GHz}$. Again, an increase in the bump height results in very little change in the gain across the frequency range. With a decrease in the height of the bumps, the increased feed to lower patch coupling causes a minor increase in gain. But minimal increase is countered by the detrimental effect on the bandwidth. Figure 4 shows the simulated far field radiation pattern of the proposed antenna at $13 \mathrm{GHz}$ for the $\mathrm{H}$-plane (Figure 4(a)) and E-plane (Figure 4(b)). A front to back ratio of approximately $18 \mathrm{GHz}$ is observed. The cross-polarized components of the radiated fields are also quite low, which is indicative of stacked patches with a hi-lo permittivity material configuration [2]. 


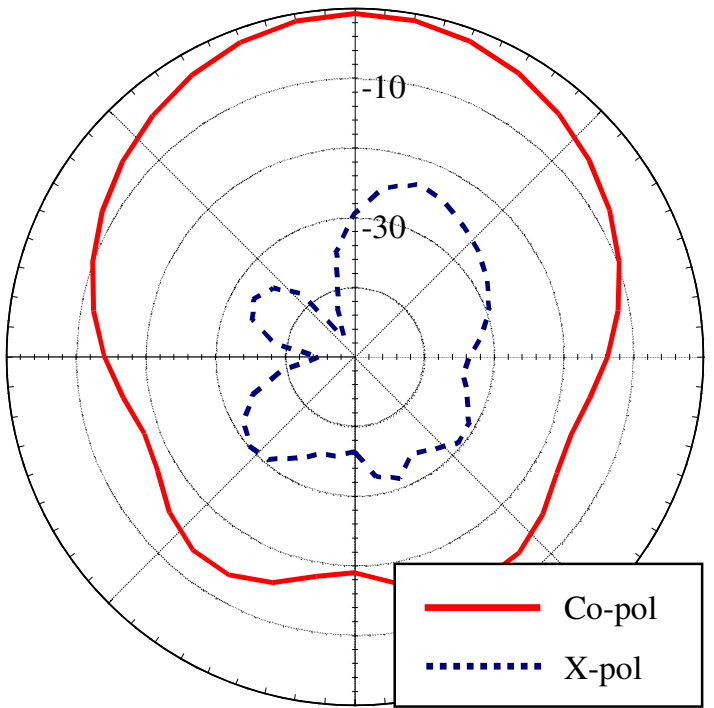

(a)

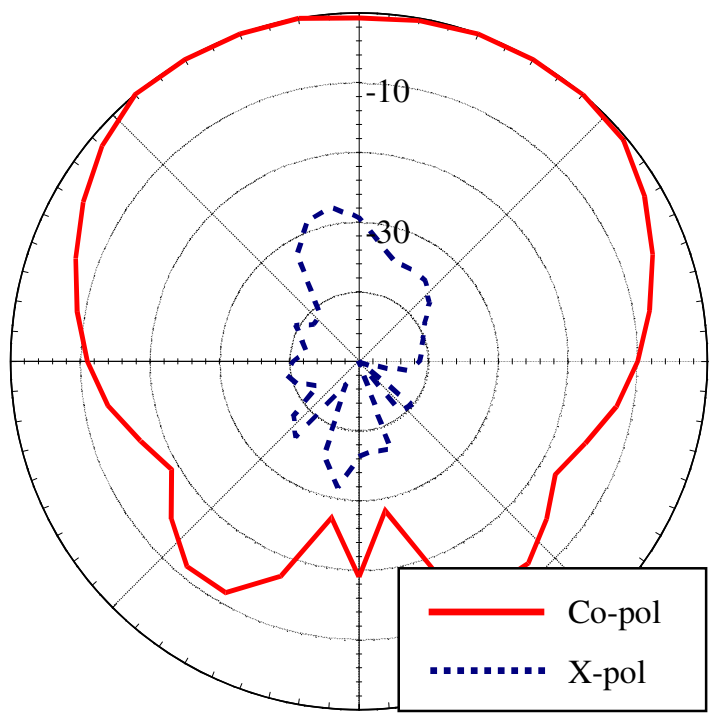

(b)

Figure 4. Simulated radiation pattern of the proposed flip-chip antenna at $13 \mathrm{GHz}$

(a) H-plane (b) E-plane.

\section{CONCLUSION}

In this paper, a flip-chip bonded stacked patch antenna structure with a proximity coupled feed is presented. Due to the high permittivity feed material, this antenna is compatible with MMICs, and uses a high and low dielectric constant material combination to achieve wideband performance. The simulation results showed that the objective of achieving a good bandwidth performance was achieved, with an impedance bandwidth of $23.8 \%$ over the frequency range from $11.5 \mathrm{GHz}$ to 14.6 $\mathrm{GHz}$. The flip-chip antenna produced a gain of 5.3 $\mathrm{dBi}$ at $13 \mathrm{GHz}$. A parameter study showed how a change in the height of the flip-chip bumps can affect the bandwidth and radiation efficiency. The design and simulation of this flip-chip antenna structure has been addressed in this paper, and the experimental results will be available in the near future.

\section{REFERENCES}

[1] W. R. Deal, N. Kaneda, J. Sor, Y. Qian and T. Itoh, 'A new quasi-yagi antenna for planar active antenna arrays', IEEE Trans. Microwave Theory and Techniques, 2000, vol. 48, no. 6, pp. 910-918.

R. B. Waterhouse, 'Stacked patches using high and low dielectric constant material combination', IEEE Trans. Antennas Propag., 1999, vol. 47, pp. 1767-1771.

[3] R. B. Waterhouse and W. S. T. Rowe, 'MMIC compatible printed antennas', Electronics Letters, 2003, vol. 39, no. 21, pp., 1493-1495.

[4] S. Mestdagh, W. DeRaedth and G. A. E. Vandenbosch, 'CPW-fed stacked microstrip antennas', IEEE Trans. Antennas Propag., 2004, vol. 52, no. 1, pp. 74-83.

S. Aoki, H. Someta, S. Yokokawa, K. Ono, T. Hirose and Y. Ohashi, 'A flip chip bonding technology using gold pillars for millimeter-wave applications', IEEE MTT-S International Symposium Digest, 1997, vol. 2, pp. 731-734. 